\title{
Literature Contributions of a Pediatric Cardiologist to Adult Congenital Heart Disease - Part III
}

\author{
P. Syamasundar Rao* \\ Professor of Pediatrics \& Medicine, Emeritus Chief of Pediatric Cardiology, University of Texas at Houston, McGovern Medical School, USA
}

\begin{abstract}
The prevalence of congenital heart defects (CHDs) in adults has increased during the last few decades such that now there are more adults with CHD than children. Advances in the diagnosis and management of CHD in children has resulted in this phenomenon. This review indicated that transcatheter methods are successful in relieving obstruction associated with coarctation of the aorta, pulmonary stenosis and aortic stenosis. With regard to cyanotic CHD, the majority of patients presenting in adulthood are likely to be those that have had corrective or palliative surgery during infancy and childhood, although on rare occasion uncorrected defects may present for the first time in adulthood. Pathophysiologic effects of right to left shunt associated with cyanotic CHD are reviewed. Brief description of the anatomy of the most common cyanotic CHDs, namely, tetralogy of Fallot, transposition of the great arteries, tricuspid atresia, total anomalous pulmonary venous connection, and truncus arteriosus was presented followed by a discussion of management strategies of the residual defects. Adults who did not have surgical correction in childhood should undergo surgical correction, but they may have a higher risk than that seen in children
\end{abstract}

\section{Introduction}

The author's contributions to the literature in relation to adult congenital heart defects (CHDs) were named and recent documentation of higher prevalence of CHDs in adults was cited in the Part I of these reviews. Also discussed was occlusion of aorto-pulmonary communications, namely patent ductus arteriosus and aortopulmonary windows. In Part II, closure of the defects in the atrial septum, namely, secundum atrial septal defects (ASDs) and patent foramen ovlae (PFO) were be reviewed. In this Part III, the remaining contributions of the author will be examined.

\section{Coarctation of the aorta}

The author has reviewed the role of balloon angioplasty in the management of coarctation of the aorta in adults [1-4] and this will only be briefly described here. Lababidi and his associates [5] were the first to use the balloon angioplasty technique in adults; they performed balloon angioplasty of CoA in a 27-year-old man with a resultant drop in the peak systolic pressure gradient across the aortic narrowing from 70 to $15 \mathrm{mmHg}$, along with angiographic improvement, and improved hypertension (190/124 $\mathrm{mmHg}$ vs. $130 / 80 \mathrm{mmHg}$ ). This was followed by a report of their additional experience [6] with balloon dilatation of native CoA in eight consecutive patients, aged 19 to 30 years (25 \pm 5 years) (Figure 1). Follow-up clinical and echo-Doppler evaluation one year later continued to show good results with a $<15 \mathrm{mmHg}$ peak systolic blood pressure difference between the arms and legs, measured by cuff. Other investigators reported similar results, which were tabulated elsewhere [3] for the interested reader. It would appear that the results of balloon angioplasty in adult subjects are generally similar to those reported in children. However, the recent trend [4,7] is to use stents for treating all types (native, post-surgical, post-balloon and those with aneurysms) of aortic coarctation in adults with consequent lessening the need for isolated balloon angioplasty.

In a collaborative review with Dr. Gautam Singh of St. Louis University, the author discussed echocardiographic evaluation of coarctation of the aorta in adults [8]; the two-dimensional (2D) and Doppler features of coarctation were discussed, and a detailed analysis of pressure gradient estimation was presented. The strengths and pitfalls of $2 \mathrm{D}$ and Doppler echocardiography were discussed. Its usefulness in the non-invasive monitoring of the results of balloon/surgical therapy was also emphasized. The interested reader may review this publication for further details [8].

\section{Pulmonary stenosis}

The author has reviewed the results of balloon pulmonary valvuloplasty (BPV) in adult subjects in multiple publications in the past $[1,9-12]$. The indications, the procedure of BPV and the results are similar to those in children. The exceptions are the use of the Inoue balloon (the advantage of the Inoue balloon over conventional balloons is that it is possible to increase the balloon diameter, making stepwise dilatation feasible) [13] and a higher incidence of the development of infundibular obstruction [14] in adults. In these reviews it was concluded that successful BPV is feasible in adults, and balloon valvuloplasty was recommended as the ideal treatment for the management of PS for this group of patients as well [12]. The interested reader is referred to a relatively recent review on this subject [12].

${ }^{\star}$ Correspondence to: P Syamasundar Rao, Professor of Pediatrics \& Medicine, Emeritus Chief of Pediatric Cardiology, University of Texas at Houston, McGovern Medical School, Houston, Texas, USA, Tel: 832-2691050, E-mail: P.Syamasundar.Rao@uth.tmc.edu

Key words: coarctation of the aorta, pulmonary stenosis, aortic stenosis, congenital heart defects, cyanotic heart defects, tetralogy of Fallot, transposition of the great arteries, tricuspid atresia, total anomalous pulmonary venous connection, truncus arteriosus

Received: August 04, 2020; Accepted: August 17, 2020; Published: August 24 2020 


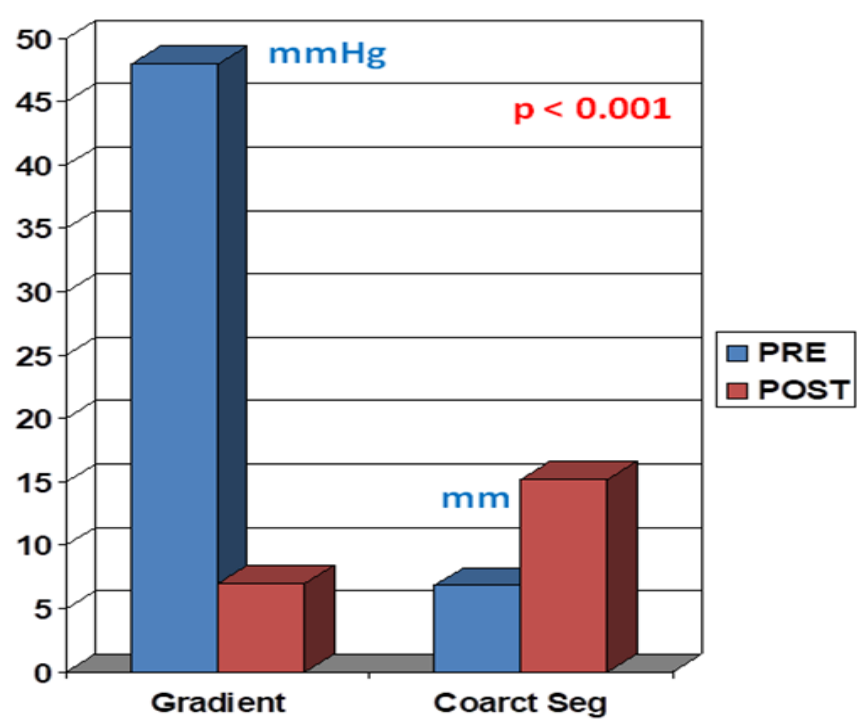

Figure 1. Bar graph illustrating the results of balloon angioplasty of native aortic coarctation in adult patients reported by Attia and Lababidi. Note the significant reduction $(\mathrm{p}<0.01)$ in peak-to-peak gradients (in $\mathrm{mmHg}$ ) across the coarctation, and the increase $(\mathrm{p}<0.01)$ in the size of the coarcted aortic segment (Coarct $\mathrm{Seg}$ ) (in $\mathrm{mm}$ ). PRE, before balloon angioplasty; POST, after balloon angioplasty. Reproduced from Reference 4.

\section{Aortic stenosis}

Following the description of balloon aortic valvuloplasty (BAV) by Lababidi et al. $[15,16]$, the technique was extended to adult patients with calcific aortic stenosis, with the initial impression that the technique is valuable in the management of elderly people with this condition, as reviewed elsewhere [17-19]. Subsequently however, the relief of obstruction was found to be temporary and transient, and at the current time, elderly patients with calcific aortic stenosis are candidates for transcatheter aortic valve replacement (TAVR) [20]. The results of BAV for non-calcific aortic stenosis in adolescents and adults are similar to those seen in children (see Table in reference 20), as reviewed elsewhere [20,21].

\section{Cyanotic CHD in adults}

The author has reviewed the issues related to what an adult cardiologist should know about cyanotic CHDs in adult subjects $[22,23]$. As reviewed in Part I of these reviews, the prevalence of CHDs in adults has increased during the last two to three decades such that now there are more adults with CHDs than children. According to a recent estimate, there are more than one million adults with $\mathrm{CHDs}$ in the USA alone. The advances made in the diagnosis and successful management of CHDs in infants and children appear to be the reasons for such a phenomenon [24]. In these reviews, only cyanotic CHDs were addressed $[22,23]$; some of the acyanotic CHD were addressed in Parts I and II as well as in first section of this Part III. The majority of the cyanotic CHD patients are likely to be those who have had corrective or palliative surgery in infancy and childhood, although occasionally an uncorrected CHD may present for the first time in adulthood. Some patients who have undergone surgical "correction" earlier may have residual abnormalities which may become significant with time.

Pathophysiologic effects of right-to-left shunts associated with cyanotic CHDs: Patients who have uncorrected CHD or who were palliated by aorto-pulmonary shunts, pulmonary artery (PA) banding or bidirectional Glenn are likely to be cyanotic because of intracardiac right-to-left shunting. This right-to-left shunt results in arterial desaturation and cyanosis. Clubbing or hypertrophic osteoarthropathy usually develops after six to 12 months of cyanosis and is manifested by thickening and widening of ends of the fingers and toes with convex nails. The decreased arterial oxygen saturation stimulates the production erythropoietin from the kidney, which in turn stimulates the bone marrow to produce more red blood cells, causing polycythemia. This compensatory mechanism increases the oxygen carrying capacity and increases oxygen delivery to the tissues. While polycythemia is useful, when haematocrits exceed $70 \%$, it becomes counter-productive because it produces hypervolemia, increases yield shear stress and high blood viscosity which in turn increases peripheral vascular resistance, reduces cardiac output and decreases oxygen delivery to the tissues. Symptoms of polycythemia, namely, headache, chest pain, fatigue, muscle cramps or irritability develop. Furthermore, high hematocrit increases the risk of cerebro-vascular accidents. Polycythemia should be treated by erythropheresis instead of phlebotomy. Some patients may develop iron deficiency and should receive oral iron therapy. Cyanotic CHD patients with significant arterial desaturation and polycythemia tend to have coagulation problems; it is likely that these abnormalities are related decreased plasma volume. Patients with low oxygen saturation (60\% or less) and high hematocrit should be screened for prothrombin time, partial thromboplastin time and platelet count prior to any cardiac or non-cardiac surgery, including dental extractions. Most of the coagulation abnormalities can be reversed by erythropheresis mentioned above and should be performed prior to cardiac or noncardiac surgery, cardiac catheterization, and catheter interventions. Other problems associated with polycythemia are hyperuricemia, gout, and uric acid nephropathy and therefore, serum uric level should be monitored in adults with cyanotic CHD. Finally, the patients with intra-cardiac right-to-left shunting are candidates for developing brain abscess, cerebro-vascular accidents (CVAs) and transient ischemic attacks (TIAs) presumably secondary to paradoxical embolism because of right to left shunt (by bypassing the pulmonary filtering mechanism).

The most important of the cyanotic CHDs, the so called " $5 \mathrm{Ts",}$ namely, tetralogy of Fallot, transposition of the great arteries, tricuspid atresia, total anomalous pulmonary venous connection, and truncus arteriosus will be reviewed.

\section{Tetralogy of Fallot}

Tetralogy of Fallot (TOF) is made up of four abnormalities, namely, ventricular septal defect (VSD), pulmonary stenosis (PS), right ventricular (RV) hypertrophy, and dextroposition of the aorta. Total surgical correction by closure of VSD and relief of the infundibular, pulmonary valvar and/or pulmonary arterial (PA) obstruction is usually performed in infancy with very little mortality. When total correction in the neonatal period or infancy is not feasible because of pulmonary atresia, pulmonary arterial (and/or annular) hypoplasia, "smallish" left ventricle, and/or anomalous course of a major coronary artery in the right ventricular infundibulum, palliative surgery to augment pulmonary blood flow by a classic [25] or modified [26] Blalock-Taussig shunt or RV to PA non-valved conduit (GoreTex graft) is recommended; most surgeons prefer modified Blalock-Taussig shunt [26] using an interposition Gore-Tex graft between right or left subclavian (or brachio-cephalic) arteries to the ipsilateral pulmonary artery. In these patients total surgical correction is performed later in childhood. Some variants of TOF such as pulmonary atresia, multiple aorto-pulmonary collateral arteries (MAPCAs), absent pulmonary valve syndrome may require RV to PA valved conduit (usually a homograft) at the time of repair. It is unusual for an un-operated TOF patient to present in adulthood, particularly in the developed countries, such patient can be operated upon, although at a higher risk than childhood surgery. The 
long-term issues for patients with operated TOF are residual shunts, arrhythmias, residual RV outflow tract and branch PA obstruction, pulmonary insufficiency, dilated aortic root, and aortic insufficiency.

Residual shunts: Residual VSDs, if present are usually small, tend to close spontaneously and rarely require repeat surgery. Atrial septal defects (ASDs) or patent foramen ovale (PFO) are usually closed at the time of total correction of TOF. However, some surgeons do not close these defects in order to allow right to left shunt to maintain cardiac output in the immediate post-operative period. If such an atrial defect causes significant left to right shunt in adolescence or adulthood, transcatheter and rarely surgical closure may become necessary $[27,28]$.

Arrhythmias: Ventricular tachycardia and sudden death were documented in some follow-up studies [29-32]. The frequency of sudden death is estimated to be $0.27 \%$ during the first 25 years following surgery while it is slightly higher at $0.94 \%$ after 25 years [33]. The risk factors associated with sudden death were sustained ventricular tachycardia, significant pulmonary insufficiency, QRS duration $>180$ $\mathrm{ms}$, and left ventricular dysfunction [32]. Non-invasive studies such as Echo and MRI and ambulatory ECG monitors such as Holter and event recorders to detect the abnormalities and address them as and when they are found is suggested. Invasive electrophysiological studies [34] may be necessary in patients who are symptomatic or have a high risk. Other arrhythmias such as heart block, sinus node dysfunction, atrial fibrillation/flutter and supraventricular tachycardia may be seen less often [35].

Branch pulmonary artery stenosis: Stenosis of the branch pulmonary arteries may occur in some patients; this may be related inadequately relieving the obstruction at the time of initial surgery or related to distortion secondary to prior shunt procedures. The indications for intervention are not clearly defined but the author recommends intervention if the proximal pulmonary artery/right ventricular systolic pressures are in excess of half systemic pressure in patients with bilateral stenosis and less the $30 \%$ flow distribution to the ipsilateral lung in cases with unilateral stenosis [36,37]. In the unilateral branch PA stenosis, the peak-to-peak pressure gradients are not useful in determining the degree of obstruction. Relief of the stenosis is indicated with less severe degrees of obstruction in patients who have pulmonary regurgitation. Balloon angioplasty is helpful in discrete obstructions while long segment stenoses require stent therapy [36,37]. An example is illustrated in (Figure 2). If the lesions not amenable to percutaneous therapy, surgical intervention with patch angioplasty maybe needed.

Right ventricular (RV) outflow tract obstruction: Residual RV outflow tract obstruction may be present or may develop later at the infundibular, valvar or supravalvar pulmonary artery level. The indications for intervention are RV systolic pressure more than half systemic pressure. Residual infundibular (subpulmonary) and supravalvar pulmonary artery stenosis require surgical intervention. Valvar stenosis may be satisfactorily relieved by balloon pulmonary valvuloplasty [38].

Right ventricle to pulmonary artery conduit stenosis: As mentioned previously, some types of TOF need right ventricle to pulmonary artery valved conduit (usually a homograft) at the time of initial surgical correction. Frequent development of calcific degeneration and obstruction of bioprosthetic right ventricular-topulmonary artery conduits has been observed. The indication for intervention, again is elevated right ventricular systolic pressure $>50 \%$ of left ventricular systolic pressure. Balloon valvuloplasty of these valves has produced some relief of obstruction with nominal extension of the life span of the conduit [39]. However, stents (Figure 3) may be more effective in extending the life of the conduit [37,40,41]. More recently, trans-catheter delivered pulmonary valve replacement has been used and is under active investigation [42-45].

Dilated aortic root and aortic insufficiency: Enlargement of the aortic root with mild aortic insufficiency is commonly seen in TOF and typically needs no intervention. In some studies, structural abnormalities of the aortic wall have been observed. Dissection and aneurysmal dilatation are extremely rare, but have been reported [46,47].

Pulmonary insufficiency: Since the pulmonary valve is structurally abnormal plus the type of repair that is undertaken at the time of surgery, pulmonary insufficiency is present in all most all patients. This is more so in patients who had trans-annular patch. With time, progressive dilatation of the right ventricle ensues. Follow-up of such patients to monitor the size of the RV and function is essential. Magnetic resonance imaging (MRI) is probably the most useful in this regard. RV end-diastolic volume $>160 \mathrm{ml} / \mathrm{m} 2$ is generally considered an indication for treatment. The pulmonary valve should be replaced prior to deterioration of RV function. Surgical or transcatheter valve replacements are available options. In some patients, replacement of the pulmonary valve with a homograft or bio-prosthetic valve becomes necessary in childhood. These replaced pulmonary valves deteriorate causing stenosis and/or regurgitation and may require re-replacement. Currently trans-catheter delivered pulmonary valves [42-45] are being used to instead of surgical replacement. Further investigation in this type of treatment is in order.

\section{Transposition of the great arteries}

In transposition of the great arteries (TGA), the most common $\mathrm{CHD}$ in the neonate, the aorta arises from the morphologic RV and

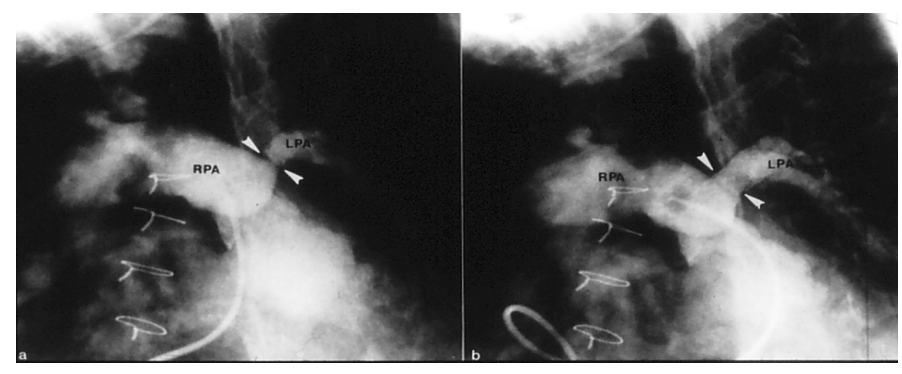

Figure 2. Selected cineangiographic frames from main pulmonary artery injection in a sitting-up view demonstrating an enlarged right pulmonary artery (RPA) and small and markedly narrowed (arrowheads) left pulmonary artery (LPA) prior to (a) and following (b) stent (arrowheads) implantation in a patient who had surgical correction of several years previously. Reproduced from Rao PS. J Cardiovasc Dis Diagn 2013; 1:104.

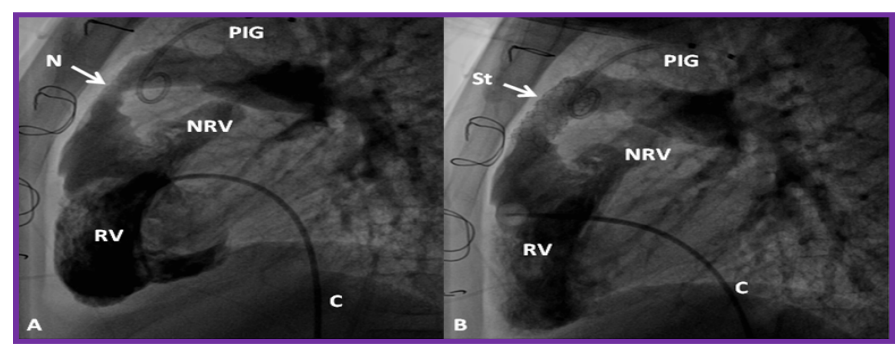

Figure 3. Selected cineangiographic frames from lateral view, demonstrating the effect of stent $(\mathrm{St})$ deployment across the narrowed $(\mathrm{N})$ right ventricular $(\mathrm{RV})$ outflow tract (arrow). The narrowed site (A) and RV cineangiogram after St implantation (B) show the enlargement of the stenotic site. On pressure pullback (not shown), there was an almost complete abolition of the systolic pressure gradient across this region. Blindly ending native RV outflow tracts (NRV) are also shown in both A and B. C, catheter, PIG, pigtail catheter in the aorta. Reproduced from Reference 41. 
the PA from the morphologic left ventricle. In the most common form, referred to as complete transposition or d-TGA, the atria are normal in position (atrial situs solitus), there is atrio-ventricular concordance (right atrium connected to the RV and the left atrium to the left ventricle), $\mathrm{d}$ loop of the ventricles (RV is on the right and left ventricle on the left), ventriculo-arterial discordance (aorta arising from the RV and the PA from the left ventricle) and the aortic valve is located to the right of pulmonary valve (d-TGA). Three types of TGA are recognized [48]. TGA with intact ventricular septum, TGA with VSD, and TGA with VSD and PS. For babies with intact ventricular septum as well as those with VSD, the treatment initially was physiological correction by atrial switch (Senning and Mustard) procedures [49-51]; subsequently anatomic correction by arterial switch (Jatene) procedure [52] came into vogue. But the babies with TGA, VSD and PS are treated with Rastelli operation $[53,54]$.

Atrial switch operation: The babies that underwent atrial or venous switch (Senning and Mustard) procedures in 1960s thru' 1980s have reached adulthood and many of these patients have been reported to develop complications and these include arrhythmias, baffle obstructions, baffle leaks, tricuspid insufficiency and RV dysfunction.

Arrhythmias: Bradycardia due to sinus node dysfunction and supra-ventricular tachycardia, mostly related to atrial surgery have been seen frequently; there is decreasing frequency of sinus rhythm with increasing time from the date of surgical repair by Mustard/Senning procedure $[55,56]$. These rhythm disturbances should be treated with anti-arrhythmic drugs, radiofrequency ablation, pacemakers and intracardiac defibrillator (ICD), as deemed suitable. This should be undertaken in collaboration with electrophysiologists familiar with arrhythmias associated with CHD. There is also a higher prevalence of sudden death $[31,57]$; the risk factors are unknown, but are likely to be related to arrhythmias [57].

Baffle obstructions: Baffle obstruction develop in nearly $10 \%$ of the patients [56]. Systemic venous obstruction is more frequently seen than pulmonary venous stenosis. The superior vena caval (SVC) obstruction is more often present than inferior vena caval stenosis [58]. Symptoms such as upper body edema indicative of SVC syndrome are rare and are usually detected by echo-Doppler studies, angiography or MRI performed either during routine follow-up or prior to considering placing pacemaker catheters. Balloon angioplasty of stenosed baffle obstruction (Figures 4 and 5 ) is often successful [58,59], however long-segment stenotic lesions would necessitate stent implantation (Figure 6) [36,37].

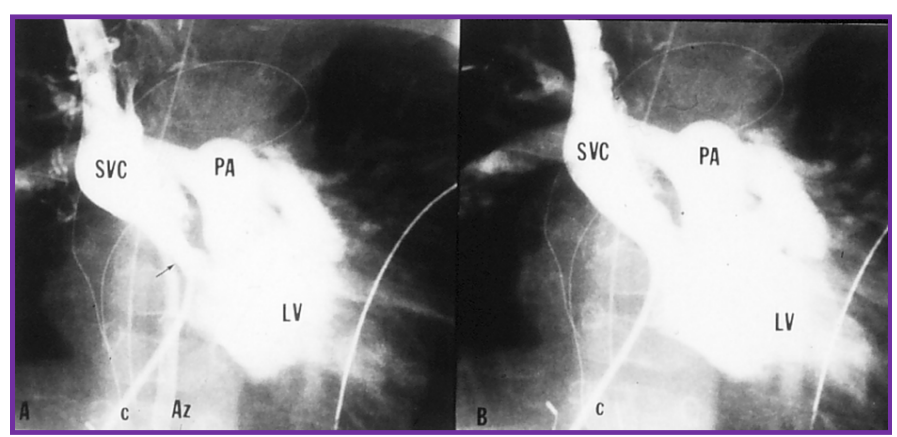

Figure 4. Selected cineangiographic frame from superior vena cava (SVC) injection in posterio-anterior view demonstrating stenosis (arrow) of the SVC baffle (A - PRE) in a patient who had Mustard procedure in the past. Following balloon angioplasty (B - POST), the narrowed segment improved (arrow). The azygos vein (Az) seen in A is no longer seen in B, presumably related relief of SVC obstruction following balloon angioplasty. C, catheter; LV left ventricle; PA, pulmonary artery. Reproduced from Rao PS, Wilson AD. (1992) Am Heart J 123: 244-248.

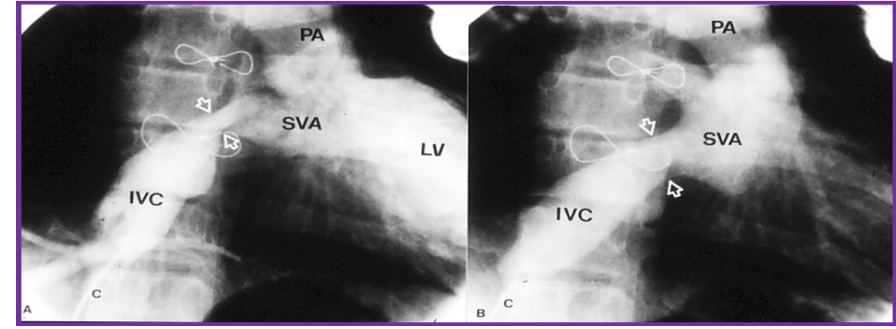

Figure 5. Selected cineangiographic frame from inferior vena cava (IVC) injection in right anterior oblique view demonstrating stenosis (arrows) of the IVC baffle (A - PRE) in a patient who had Mustard procedure several years previously. Following balloon angioplasty (B - POST), the narrowed segment improved (arrows). C, catheter; LV left ventricle; PA, pulmonary artery; SVA, systemic venous atrium. Reproduced from Rao PS, Wilson AD. (1992) Am Heart J 123: 244-248.

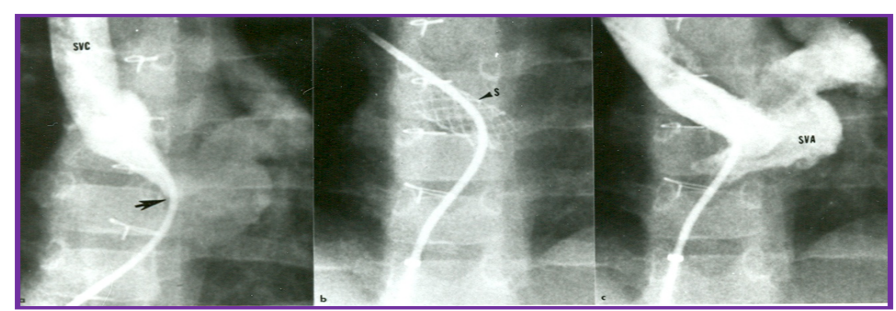

Figure 6. Selected cineangiographic frame from superior vena cava (SVC) injection in posterio-anterior view demonstrating severe, long segment stenosis (arrow) of the SVC baffle (a - PRE) in a patient who had Mustard procedure in the past. Following stent (arrow) implantation (b - STENT), the narrowed segment improved (c - POST). SVA, systemic venous atrium. Reproduced from Rao PS, Indian Heart J 2001; 53:714-30.

Baffle leaks: Baffle leaks are typically small and may not be hemodynamically significant. Although they may be detected by color Doppler examination, they are best detected by selective vena caval cineangiograms. Indication for intervention are significant left to right shunt (Qp:Qs > 1.5:1), right to left shunt and transvenous pacemaker wires. Percutaneous device closure is preferable to surgical closure [60,37].

RV dysfunction and tricuspid insufficiency: In the Senning and Mustard operations, the RV remains the systemic ventricle and is required to pump into the systemic circuit. RV dysfunction with or without tricuspid insufficiency may develop in nearly $15 \%$ of patients in their second and third decades of life [56,61]. Initially, treatment with the usual anti-congestive measures along with angiotensin-converting enzyme (ACE) inhibitors for afterload reduction, may be started. Severe tricuspid insufficiency may be addressed with repair or replacement of the tricuspid valve if the RV systolic function is preserved. In patients with severe CHF, double switch operation with retraining the left ventricle and heart transplant are available alternative treatment methods. Now that the venous switch operations are rarely performed, the frequency with which the above described complications are seen has remarkably decreased.

Arterial switch operation: The infants who underwent arterial switch (Jatene) procedures in 1980s and 1990s are just reaching adulthood. The majority of patients $(>95 \%)$ remain asymptomatic 25 years after surgery [62]. Residual supravalvar aortic stenosis, supravalvar PA stenosis and branch PA stenosis may be seen in some patients. If the gradients across this stenosis are high, transcatheter (balloon angioplasty or stent) or surgical therapy may be needed. Neoaortic dilatation with aortic insufficiency may be seen, but severe insufficiency is seen in less than $1 \%$ of the patients [63]. Coronary artery problems can occur and were seen in $7 \%$ of patients undergoing selective coronary angiography [64]. 
Rastelli operation: As reviewed in the RV to PA Conduit Stenosis section of TOF, calcific degeneration and development of obstruction of bioprosthetic right ventricular-to-pulmonary artery conduits do occur and the management is similar to that described in that section. Conduit valve insufficiency may also develop. Restriction at the VSD level causing sub-aortic obstruction can also develop in some patients and when severe, surgical intervention is necessary.

\section{Tricuspid atresia and other single ventricle defects}

In tricuspid atresia there is congenital absence or agenesis of the morphologic tricuspid valve [65]. The most common muscular type of tricuspid atresia is characterized by a dimple or a localized fibrous thickening in the floor of the right atrium and is most commonly classified based on associated defects [66], namely, relationship of great arteries and status of pulmonary arteries (atresia, stenosis or normal). The left ventricle is large, and the RV is small and hypoplastic. VSD may be large, small or non-existent. The VSD is most commonly located in the muscular septum and the majority of the VSDs are restrictive and produce sub-pulmonary stenosis in patients with normally related great arteries and subaortic stenosis in patients with transposition of the great arteries [67-70]. There is only one functioning ventricle in this lesion. There are a number of other CHDs that have one functional ventricle and such defects are: double-inlet left ventricle (single ventricle), pulmonary atresia with intact ventricular septum with RV hypoplasia, hypoplastic left heart syndrome, unbalanced common atrioventricular canal and any other complex CHD with hypoplasia of one of the ventricles. These children need palliative surgical intervention at the time of presentation, frequently in the neonatal period; this is followed by "corrective" surgery at a later date. Since these patients have only one functioning ventricle, this ventricle is used to pump into the systemic arterial circuit and the systemic venous return is diverted into the pulmonary arteries without the use of a ventricle. This concept was proposed, and the procedures were performed by Fontan [71] and Kreutzer [72] in the early 1970s. Since this procedure cannot be performed in the neonate and young infant because of high pulmonary artery pressure/resistance, it is undertaken by multistage surgery. Since the original description $[71,72]$, this procedure has undergone a number of modifications, as reviewed elsewhere $[73,74]$ and the current approach is staged total cavo-pulmonary connection (TCPC) [75] with extracardiac conduit and fenestration with subsequent device closure of the fenestration $[73,74]$.

Stage I. At the time of initial presentation, modified BlalockTaussig shunt [26] is performed for infants with pulmonary oligemia and banding of the pulmonary artery [76] is performed for babies with increased pulmonary flow. If adequate pulmonary flow is present, no intervention is necessary at presentation. Norwood procedure [77] with either a modified Blalock-Taussig [26] or Sano [78] shunt is performed in babies with hypoplastic left heart syndrome.

Stage II. At about the age of six months, bi-directional Glenn procedure is performed by anastomosis of the superior vena cava to pulmonary artery, end to side. Previously created shunts are closed. If there are any other residual defects, these are corrected at the same time.

Stage III. One year later, diversion of IVC blood into the pulmonary arteries is performed with an extra-cardiac conduit. Most surgeons create a 4 to $6 \mathrm{~mm}$ sized fenestration between the conduit and the atrial mass in all most all patients; the fenestration is closed by transcatheter methodology six to twelve months later.

Patients who have had a Fontan correction for tricuspid atresia and other single ventricle defects may develop arrhythmias, obstructed
Fontan pathways, cyanosis and CVAs/TIAs, thrombi, collateral vessels, and protein-losing enteropathy. These problems appear to be more frequent with patients who have had the atrio-pulmonary type of Fontan procedure $[71,72]$ than those who had a staged total cavo-pulmonary connection [73-75]. Most patients who had the classic atrio-pulmonary connection have reached adulthood and patients who had staged TCPC are just reaching adulthood. It appears that the complications during follow-up are more frequent with classic Fontan than with TCPC. The identified problems are discussed below.

Arrhythmias: The arrhythmias are common with atrio-pulmonary connections (old Fontan). These are mostly atrial arrhythmias such as atrial flutter/fibrillation and supraventricular tachycardia and are thought to be related macro re-entry circuits. First, they are managed with anti-arrhythmic drugs, although this is with variable success. Hemodynamic and angiographic assessment should be carry out. If obstructive lesions are detected in the Fontan circuit, they should be addressed with either balloon angioplasty or stent or even surgery, as deemed appropriate, to relieve the obstruction. The next step is radiofrequency ablation; the reported success rate is in the order of $80 \%$ [79]. However, recurrence rate following ablation is high (30 to 40\%) [79]. For resistant arrhythmias, Fontan revision [80] with debulking of the atrial mass, conversion to TCPC and Maize procedure may become necessary. In some patient's atrioventricular block and sick sinus syndrome may be develop; pacemaker insertion may become necessary in such patients. Fortunately, ventricular arrhythmias are less frequent.

Obstructed Fontan pathways: Obstructive lesions may develop at the superior (SVC) or inferior (IVC) vena caval levels but are less frequent than those of branch PAs. Because of poor echo windows, MRI and magnetic resonance angiography (MRA) may be necessary in adolescents and adults to define these obstructions. Alternatively, cardiac catheterization and angiography may be performed to confirm or exclude such obstruction. If significant obstruction is found, balloon angioplasty, stent placement (Figure 7), and, if necessary, surgery should be undertaken to provide timely relief of the obstruction.

Cyanosis and cerebrovascular accidents: Fontan fenestrations created intentionally or residual defects between the lateral tunnel or extracardiac conduit and the atrial mass may cause right to left shunt because of higher Fontan conduit pressure than the atrial pressure. These residua not only produce arterial hypoxemia and cyanosis but also become sites for paradoxical embolism causing TIAs and CVAs and other systemic emboli. Transcatheter occlusion (Figure 8) of the fenestrations and atrial defects with conventional atrial septal closing devices should be performed. Test occlusion of the fenestration should be done to ensure that adequate cardiac output is maintained after closure. Some surgeons place tubular fenestrations and these may require coils, Amplatzer vascular plug (AGA Medical, Golden Valley, Minnesota) (Figure 9) or other devices. Late follow-up results after fenestration closure appear encouraging [81].

Thrombus formation: There is propensity for formation of thrombus in the Fontan circuit, presumably related to slow flow; the prevalence is as high as 15 to $30 \%[82,83]$. The thrombi may not be identified by routine transthoracic echocardiography, but may detected transesophageal echocardiography (TEE), ventilation-perfusion (VQ) scans or computed tomography (CT) angiography. Because of this reason thromboprophylaxis is generally recommended. Of the two methods used, namely warfarin and aspirin, no difference for risk of thrombosis between these regimens was found [84]. Based similar uncontrolled studies in the past most pediatric cardiologists use aspirin for thromboprophylaxis in children. Perhaps more potent drugs such 
clopidogrel (Plavix) may be used in adults. When thrombus formation in the conduit is resistant to anti-coagulant therapy, we have used stents to compress the thrombus (Figure 10) to avoid embolization into the pulmonary circuit.

Development of collateral vessels: Some patients may develop systemic arterial to pulmonary arterial (Figure 11) or systemic venous to pulmonary venous (Figure 12) collateral vessels. Systemic to pulmonary arterial collateral vessels cause left ventricular volume load while systemic venous to pulmonary venous collateral vessels produce arterial hypoxemia and form potential sites for paradoxical embolism. These should be occluded with coils or vascular plugs.

Protein losing enteropathy: In protein-losing enteropathy (PLE) loss of protein in the bowel, secondary to lymphatic distension may be

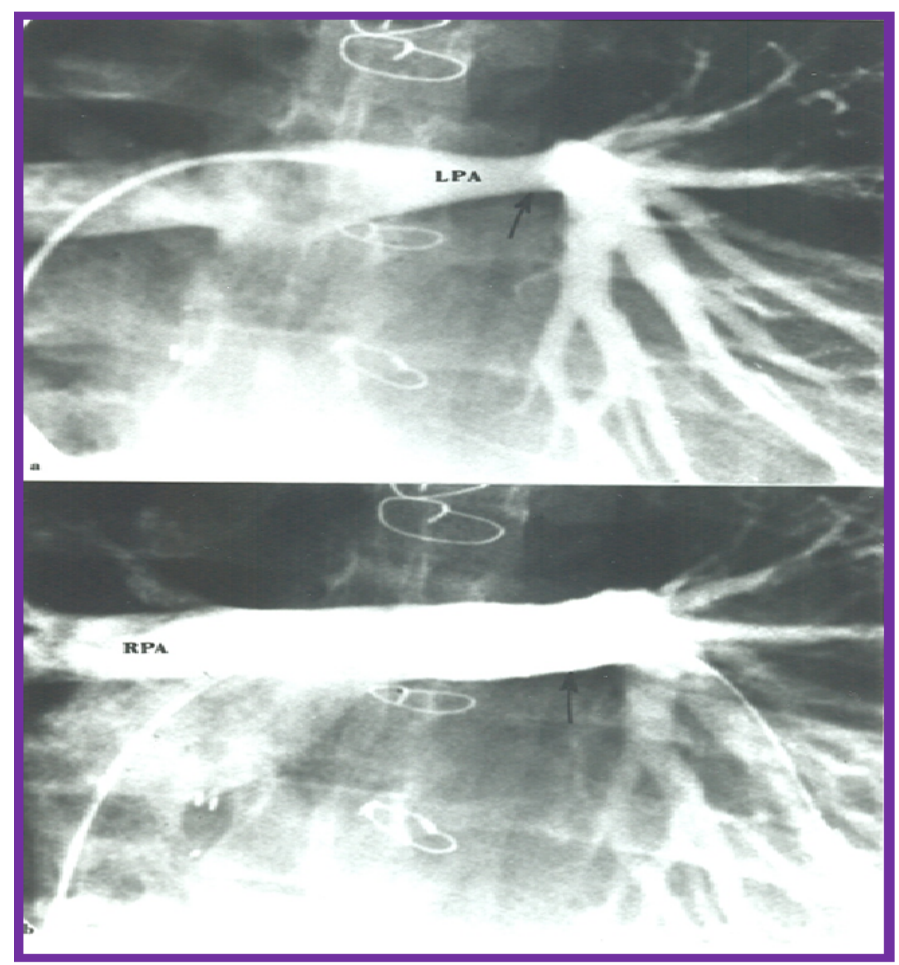

Figure 7. Selected cineangiographic frames from the pulmonary artery injection in posterioanterior view demonstrating normal right pulmonary artery (RPA) and narrowed (arrow) left pulmonary artery (LPA) prior to (a) and following (b) stent (arrow) implantation in a patient who had Fontan operation several years previously. Reproduced from Rao PS, Indian Heart J 2001; 53:714-30.

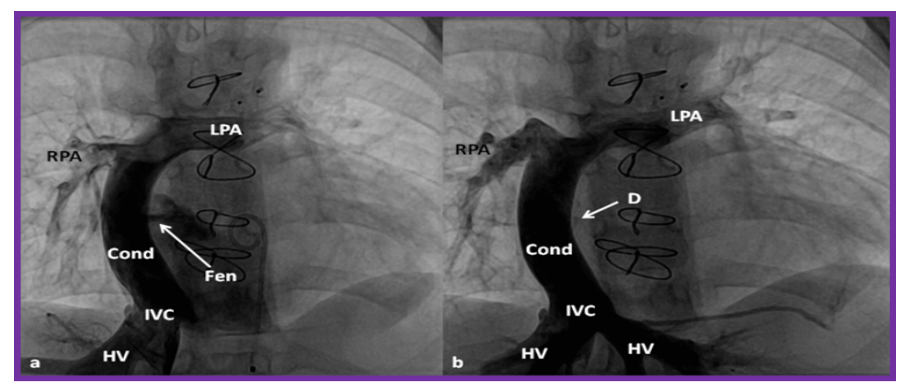

Figure 8. Selected cineangiographic frames in antero-posterior view demonstrating Stage IIIA of the Fontan procedure: diverting the inferior vena caval (IVC) flow into the pulmonary arteries via a non-valve conduit (Cond). Note the fenestration (Fen) shown by the arrow in a. The Fen is closed with an Amplatzer device (D), shown by the arrow in $\mathbf{b}$ (Stage IIIB). HV, hepatic veins; LPA, left pulmonary artery; RPA, right pulmonary artery. Reproduced from Rao PS, Indian J Pediatr 2015; 82:1147-56.

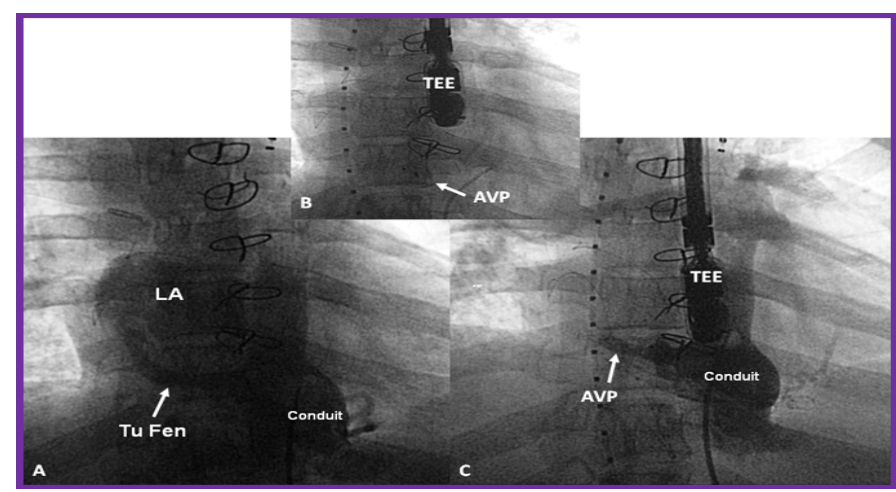

Figure 9. A. Selected cine frame from a Fontan conduit cineangiogram in antero-posterior view, demonstrating tubular fenestration (Tu Fen) with opacification of the left atrium (LA). B. The Tu Fen is closed with an Amplatzer Vascular Plug (AVP). C. A follow-up conduit cineangiogram after AVP implantation, showing complete occlusion of the Tu Fen. TEE, trans-esophageal probe. Reproduced from Rao PS. (2013) J Cardiovasc Dis Diagn 1: $104,2013$.

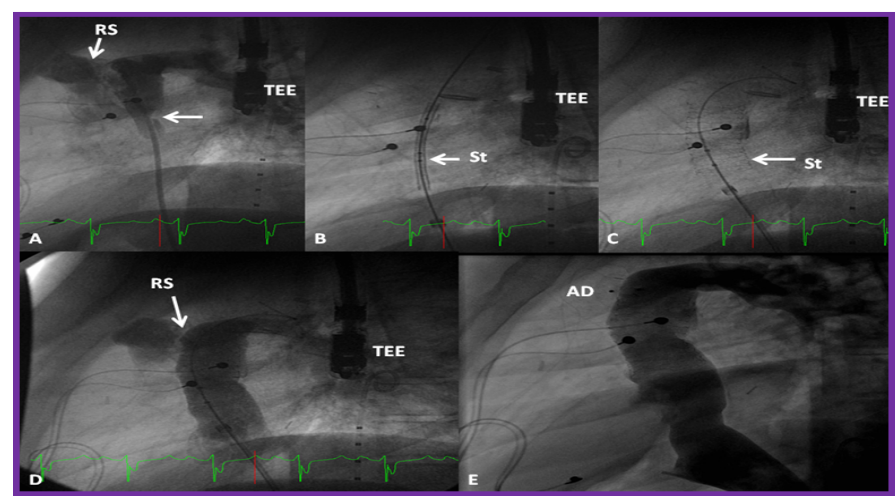

Figure 10. A. Selected cineangiographic frame of a Fontan conduit in lateral view, demonstrating a thrombus (arrow in A). B \& C. Position of the stent (St) before (B) and after (C) its complete expansion. D. Cineangiographic frame demonstrating the widely patent stent after stent deployment. Also, note the residual shunt (RS) at the superior aspect of the conduit (seen in A and D). The RS was occluded by an Amplatzer septal occluder device (AD) shortly after the cine shown in D. F. A follow-up cineangiogram one year later shows the continued patency of the conduit with no RS. TEE, transesophageal echo probe. Reproduced from Reference 41.

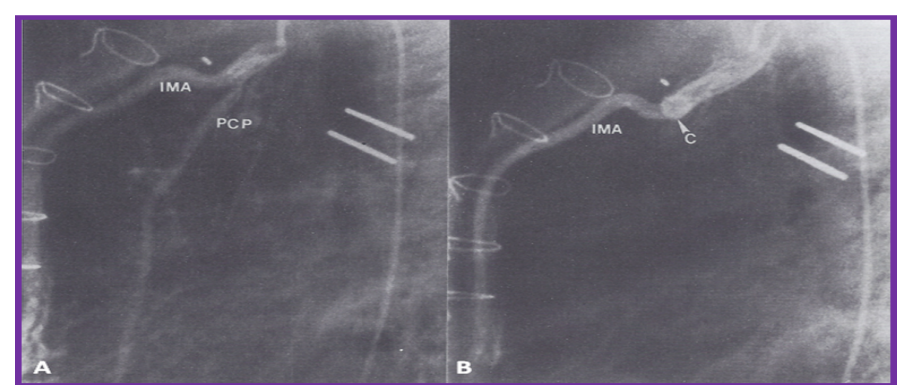

Figure 11. A (PRE). Selected cineangiographic frame from left innominate vein (L Inn) injection in posterio-anterior view demonstrating an anomalous vein (AV) opacifying the atrial mass. B (POST). Following closure with Gianturco coil (arrow) the AV is completely occluded and the systemic arterial saturation improved. Reproduced from Rao PS. (2013) J Cardiovasc Dis Diagn 1: 104, 2013.

due to elevated systemic venous pressure, although this has been seen in patients with normal Fontan pressures. PLE manifests with diarrhoea, edema, ascites, and/or pleural effusions. Serum hypoalbuminemia and elevated stool alpha-1-antitrypsin levels are suggestive of the diagnosis. PLE may be confirmed with technetium 99m-labeled human serum albumin scintigraphy [85]. The etiology of PLE is not known. The prevalence of PLE appears to be lower (1.2\%) in the TCPC group than 


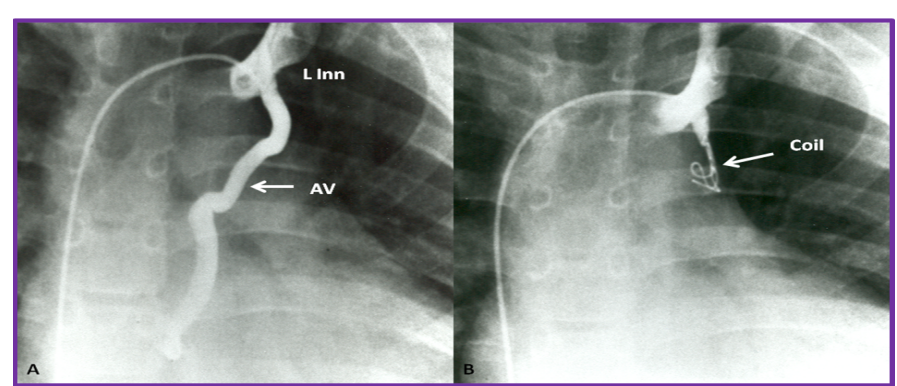

Figure 12. A. Selected cine frame from an internal mammary artery (IMA) cineangiogram in the lateral view, demonstrating multiple small collateral vessels arising from the pericardio-phrenic (PCP) branch, which resulted in a significant levophase (not shown). B Following occlusion with a Gianturco coil $(\mathrm{C})$, there is complete occlusion of this vessel.

in atriopulmonary connection patients (11.1\%) [86-88].

Because of reported high mortality rate associated with PLE quick and aggressive treatment is highly recommended. Initially, supportive measures consisting of medium-chain triglycerides diet, parental albumin administration and replacement of immunoglobulins. Obstruction in the Fontan circuit must be scrutinized and, if identified, they should be relieved by transcatheter or surgical therapy, as deemed appropriate. Similarly, aortopulmonary connections [89] and naturally occurring or prior surgical shunts should be looked for and occluded either by transcatheter or surgical techniques, as necessary. Treatment with prednisone, elementary diet, calcium replacement, regular high-molecular-weight heparin and low-molecular-weight heparin, somatostatin, high-dose spironolactone, sildenafil, and resection of localized intestinal lymphangiectasia (if demonstrated), as reviewed elsewhere [88] have been promoted with variable success.

A number of treatment methods such as reduction of right atrial pressure by creating an atrial septal defect (ASD) [90,91], conversion of atriopulmonary type of Fontan to total cavopulmonary connection [92,93], atrioventricular sequential pacing [94,95], and cardiac transplantation [96] have been attempted, with variable success. In any of the above scenarios with so called "failed Fontan," after excluding or treating obstructive lesions and residual shunts, consideration for atrioventricular sequential pacing [94,95], conversion of atrioventricular Fontan to total cavopulmonary anastomosis $[80,93,97]$, and cardiac transplantation $[96,98,99]$ should be given.

\section{Total Anomalous Pulmonary Venous Connection (TAPVC)}

In TAPVC, all the pulmonary veins are connected to a common pulmonary vein which is then drains into the left innominate vein, superior vena cava, coronary sinus, portal vein or other rare sites. On rare occasions, individual veins drain directly into the right atrium. The TAPVC is classified on the basis of the anatomic location to which the connecting veins drain and whether the pulmonary venous return is obstructed. Irrespective of the type, surgical correction is by anastomosis of the common pulmonary vein with the left atrium in the neonatal period or infancy is usually performed. Follow-up evaluation after surgery to detect occurrence of obstruction at the site of anastomosis of the common pulmonary vein with the left atrium and pulmonary venous obstruction is suggested. If found, they may be addressed with transcatheter or surgical therapy.

It is improbable that TAPVC patients will survive to the adult age without surgical correction. Nevertheless, some patients may present in adolescence and adulthood [100-105], apparently due to mild obstruction of the pulmonary venous return. Exercise intolerance, mild cyanosis and heart failure are usually the presenting symptoms [105].
Clinical findings are those seen with ASD. Echocardiography and other imaging studies (CT or MRI) may be required for diagnosis. Surgical correction [100-105] is by anastomosis of the common pulmonary vein with the left atrium, similar to that performed in neonates should be undertaken. Arrhythmias and tricuspid insufficiency are more common in adults with uncorrected TAPVC than in infants.

\section{Truncus arteriosus}

Truncus arteriosus is an uncommon cyanotic heart defect with a common arterial trunk (truncus) originating from the heart. The truncus gives rise to the aorta, pulmonary artery and coronary arteries [106]. A large VSD is present in the conal septum. The truncus is classified on the basis of the origin and distribution of the PAs. These patients are usually operated in the first few weeks of life; surgery [107] involves closure of VSD, disconnection of the PAs from the truncus and reconnecting them to right ventricle via a valved conduit, usually a homograft, and closure of the defect in the truncus created by disconnecting the pulmonary artery/arteries.

Development of branch pulmonary artery stenosis and RVPA conduit obstruction, requiring transcatheter and/or surgical intervention in more than half of the patients during childhood [108] has been observed. These obstructive lesions may recur in the adulthood and may require additional interventions. Issues related to right ventricle to pulmonary artery conduit stenosis have been detailed in the preceding sections on TOF and TGA. Dilatation of the neoaorta (old truncus) occurs in most of the patients during follow-up [109] with $\mathrm{Z}$-scores of $5.1 \pm 2.3$. However, no dissection or rupture has been documented. In the presence of neoaortic valve regurgitation and left ventricular dilatation, root replacement surgery [109] may become necessary.

\section{Other defects}

A number of other cardiac defects, namely, double outlet right ventricle, pulmonary atresia with intact ventricular septum, Ebstein's anomaly of the tricuspid valve, congenital corrected transposition of great arteries, mitral atresia with normal aortic root, interrupted aortic arch, and cardiac malpositions including heterotaxy syndromes which were surgically corrected or palliated in infancy or childhood (or de novo) may present with symptoms during adulthood, but are not discussed in this review; however, this information is available elsewhere [110-112] for the interested reader.

\section{Summary}

The long-term issues for patients with TOF are residual shunts, arrhythmias, residual RV outflow tract and branch PA obstruction, pulmonary insufficiency, dilated aortic root, and aortic insufficiency. The long-term problems associated with TGA depend upon the type of surgical correction the patient has had. Patients who have had atrial or venous switch (Senning and Mustard) procedures may develop arrhythmias, baffle obstructions, baffle leaks, tricuspid insufficiency and RV dysfunction, while those who had arterial switch (Jatene) procedures may have supravalvar aortic stenosis, supravalvar PA and branch PA stenosis, neoaortic dilatation with aortic insufficiency, and coronary artery obstruction. Patients who had a Rastelli operation may manifest calcific degeneration of the conduit and valve and develop obstruction of the bio-prosthetic RV-to-PA conduits. Left ventricular outflow tract obstruction at the old VSD level may develop in some patients. Patients who have had a Fontan correction for tricuspid atresia and other single ventricle defects may develop arrhythmias, obstructed Fontan pathways, cyanosis and CVAs/TIAs, thrombi, collateral vessels, 
and protein-losing enteropathy. These problems appear to be more frequent with patients who have had the atrio-pulmonary type of Fontan procedure than those who had a staged total cavo-pulmonary connection. Patients who have had correction of total anomalous pulmonary venous connection may develop obstruction at the site of anastomosis of the common pulmonary vein with the left atrium, and pulmonary venous obstruction. Patients with truncus arteriosus may develop branch PA stenosis, dilatation of the neoaorta (old truncus) and neoaortic valve regurgitation. The diagnosis and management concepts for each of the above residua were briefly reviewed. Patients who have not previously been corrected may undergo surgical correction but are likely to have higher morbidity and mortality rates than those seen in childhood.

\section{Conflict of interest}

The author has no potential conflict of interest in connection with this article.

\section{References}

1. Rao PS (1989) Balloon angioplasty and valvuloplasty in infants, children and adolescents. Current Problems in Cardiology. Yearbook Medical Publishers, Inc. Chicago, 14: 417-500.

2. Rao PS (1993) Balloon angioplasty of native aortic coarctation. In: Rao PS (Ed): Transcatheter Therapy in Pediatric Cardiology, Wiley-Liss, New York, NY, 153-96.

3. Rao PS (2005) Coarctation of the aorta. Curr Cardiol Rep 7: 425-434. [Crossref]

4. Rao PS (2015) Percutaneous management of aortic coarctation. In. Vijayalakshmi IB, ed. Cardiac Catheterization and Imaging (From Pediatrics to Geriatrics), Jaypee Publications, New Delhi, India, 433-71

5. Lababidi Z, Madigan N, Wu J, Wu JR, Murphy TJ (1982) Balloon coarctation angioplasty in an adult. Am J Cardiol 53: 350-351.

6. Attia IM, Lababidi ZA (1988) Early results of balloon angioplasty of native coarctations in young adults. Am J Cardiol 61: 930-931. [Crossref]

7. Rao PS, Seib PM (2014) Coarctation of the Aorta. Medscape Reference. Available at: http://emedicine.medscape.com/article/895502-overview.

8. Singh GK, Marino CJ, Rao PS (1997) Echocardiographic evaluation of coarctation of the aorta in adults. Cardiac Ultrasound Today 3: 111-124.

9. Rao PS (1990) Percutaneous balloon valvuloplasty/angioplasty in congenital heart disease. In: Percutaneous Valvuloplasty and Related Techniques. Bashore TM and Davidson CT (Eds), Williams \& Wilkins, Baltimore, MD, 251-277.

10. Rao PS (1993) Balloon pulmonary valvuloplasty for isolated pulmonic stenosis. In. Rao PS (Ed). Transcatheter Therapy in Pediatric Cardiology. Wiley-Liss, Inc., New York, 59-104 Chapter 6.

11. Rao PS (2000) Pulmonary valve disease. In: Valvular Heart Disease. $3^{\text {rd }}$ edition, Alpert JS, Dalen JE, Rahimtoola S (eds.), Lippincott Raven. Philadelphia, PA, 339-376.

12. Rao PS (2015) Balloon valvuloplasty for pulmonary stenosis. In. Vijayalakshmi IB, ed. Cardiac Catheterization and Imaging (From Pediatrics to Geriatrics), Jaypee Publications, New Delhi, India, 149-174.

13. Bahl VK, Chandra S, Goel A, Goswami KC, Wasir HS (1997) Versatility of Inoue balloon catheter. Int J Cardiol 59: 75-83. [Crossref]

14. Thapar MK, Rao PS (1989) Significance of infundibular obstruction following balloon valvuloplasty for valvar pulmonic stenosis. Am Heart J 118: 99-103. [Crossref]

15. Lababidi Z (1983) Aortic balloon valvuloplasty. Am Heart J 106: 751-752. [Crossref]

16. Lababidi Z, Wu J, Walls JT (1984) Percutaneous balloon aortic valvuloplasty: results in 23 patients. Am J Cardiol 54: 194-197. [Crossref]

17. Rao PS (1993) Balloon valvuloplasty for aortic stenosis. In. Rao PS (Ed). Transcatheter Therapy in Pediatric Cardiology. Wiley-Liss, Inc., New York, 105-127. Chapter 7.

18. McKay RG, Safian RD, Lock JE, Mandell VS, Thurer RL, et al. (1986) Balloon dilatation of calcific aortic stenosis in elderly patients: postmortem, intraoperative, and percutaneous valvuloplasty studies. Circulation 74: 119-125. [Crossref]

19. Cribier A, Savin T, Saoudi N, Behar P, Rocha P, et al. (1986) Percutaneous transluminal aortic valvuloplasty using a balloon catheter. A new therapeutic option in aortic stenosis in the elderly. Arch Mal Coeur Vaiss 79: 1678-1686. [Crossref]
20. Rao PS (2016) Balloon aortic valvuloplasty (Editorial). Indian Heart J 68: 592-595. [Crossref]

21. Awasthy N, Garg R, Radhakrishnan S, Shrivastava S (2016) Long term results of percutaneous balloon valvuloplasty of congenital aortic stenosis in adolescents and young adults. Indian Heart J 68: 604-611. [Crossref]

22. Rao PS (2013) What an adult cardiologist should know about cyanotic congenital heart disease? J Cardiovasc Dis Diagn 1: 104.s

23. Rao PS (2014) What the adult cardiologist should know about cyanotic congenital heart disease. In: Chopra HK, et al. (Eds), State of Art CSI Cardiology Update.

24. van der Bom T, Bouma BJ, Meijboom FJ, Zwinderman AH, Mulder BJM (2012) The prevalence of adult congenital heart disease, results from a systematic review and evidence based calculation. Am Heart J 164: 568-575. [Crossref]

25. Blalock A, Taussig HB (1945) The surgical treatment of malformations of the heart in which there is pulmonary stenosis or pulmonary atresia. J Am Med Assoc 128: 189-194.

26. De Leval MR, McKay R, Jones M, Stark J, Macartney FJ (1981) Modified BlalockTaussig shunt : Use of subclavian artery orifice as flow regulator in prosthetic systemicpulmonary artery shunts. J Thorac Cardiovasc Surg 81: 112-119. [Crossref]

27. Rao PS (2009) When and how should atrial septal defects be closed in adults? $J$ Invasive Cardiol 21: 76-82. [Crossref]

28. Rao PS (2012) Why, when and how should atrial septal defects be closed in adults In. Rao PS (Editor). Atrial Septal Defect, ISBN 978-953-51-0531-2; InTech, Rijeka, Croatia, April: 121-138.

29. Deanfield JE, McKenna WJ, Hallidie-Smith KA (1980) Detection of late arrhythmia and conduction disturbance after correction of tetralogy of Fallot. Br Heart J 44: 248253. [Crossref]

30. Gatzoulis MA, Till JA, Somerville J, Redington AN (1995) Mechanoelectrica interaction in tetralogy of Fallot. QRS prolongation relates to right ventricular size and predicts malignant ventricular arrhythmias and sudden death. Circulation 92: 231-237. [Crossref]

31. Silka MJ, Hardy BG, Menashe VD, Morris CD (1998) A population-based prospective evaluation of risk of sudden cardiac death after operation for common congenital heart defects. J Am Coll Cardiol 32: 245-251. [Crossref]

32. Gatzoulis MA, Balaji S, Webber SA, Siu SC, Hokanson JS (2000) Risk factors for arrhythmia and sudden cardiac death late after repair of tetralogy of Fallot : A multicenter study Lancet 356: 975-981. [Crossref]

33. Nollert G, Fischlein T, Bouterwek S, Böhmer C, Klinner W (1997) Long-term survival in patients with repair of tetralogy of Fallot: 36-year follow-up of 490 survivors of the first year after surgical repair. J Am Coll Cardiol 30: 1374-1383. [Crossref]

34. Khairy P, Landzberg MJ, Gatzoulis MA, Lucron H, Lambert J, et al. (2004) Value of programmed ventricular stimulation after tetralogy of Fallot repair: a multicenter study. Circulation 109: 1994-2000. [Crossref]

35. Roos-Hesselink J, Perlroth MG, McGhie J, Spitaels S (1995) Atrial arrhythmias in adults after repair of tetralogy of Fallot. Correlations with clinical, exercise, and echocardiographic findings. Circulation 91: 2214-2219. [Crossref]

36. Rao PS (2001) Stents in the management of congenital heart disease in the pediatric and adult patients. Indian Heart J 53: 714-730. [Crossref]

37. Sahu R, Rao PS (2012) Transcatheter Stent Therapy in Children: An Update. Pediatr Therapeut S5:001.

38. Rao PS (2007) Percutaneous Balloon Pulmonary Valvuloplasty: State of the Art. Cath Cardiovasc Intervent 69: 747-763. [Crossref]

39. Rao PS (1993) Balloon dilatation of stenotic bioprosthetic valves. In: Rao PS (ed): Transcatheter Therapy in Pediatric Cardiology, Wiley-Liss, New York, NY. 255-274.

40. Powell AJ, Lock JE, Keane JF, Perry SB (1995) Prolongation of RV-PA conduit life span by percutaneous stent implantation : intermediate-term results. Circulation 92: 3282-3288. [Crossref]

41. Rao PS (2020) Stents. In: Rao PS (ed) Pediatric Cardiology: How It Has Evolved Over the Last 50 Years. Cambridge Scholars Publishing, New Castle upon Tyne, ISBN-13: 9781527548886: 510-559.

42. Bonhoeffer P, Boudjemline Y, Saliba Z, Merckx J, Aggoun Y, et al. (2000) Percutaneous replacement of pulmonary valve in a right-ventricle to pulmonary-artery prosthetic conduit with valve dysfunction. Lancet 356: 1403-1405. [Crossref]

43. Lurz P, Bonhoeffer P, Taylor AM (2009) Percutaneous pulmonary valve implantation an update. Expert Rev Cardiovasc Ther 7: 823-833. [Crossref] 
44. McElhinney DB, Hellenbrand WE, Zahn EM, Jones TK, Cheatham JP, et al. (2010) Short- and medium-term outcomes after transcatheter pulmonary valve placement in the expanded multicentre US melody valve trial. Circulation 122: 507-516. [Crossref]

45. Kenny D, Hijazi ZM, Kar S, Rhodes J, Mullen M, et al. (2011) Percutaneous implantation of the Edwards SAPIEN transcatheter heart valve for conduit failure in the pulmonary position: Early phase I results from an international multicenter clinical trial. J Am Coll Cardiol 58: 2248-2256. [Crossref]

46. Rathi VK, Doyle M, Williams RB, Yamrozik J, Shannon RP, et al. (2005) Massive aortic aneurysm and dissection in repaired tetralogy of Fallot; diagnosis by cardiovascular magnetic resonance imaging. Int J Cardiol 101: 169-170. [Crossref]

47. Kim TS, Na CY, Baek JH, Yang JS (2011) Aortic root and ascending aortic aneurysm in an adult with a repaired tetralogy of Fallot. Korean J Thorac Cardiovasc Surg 44: 292-293. [Crossref]

48. Rao PS (2010) Transposition of the Great Arteries in the Neonate. Neonatology Today 5: $1-8$.

49. Senning A (1959) Surgical correction of transposition of the great vessels. Surgery 45: 966-980. [Crossref]

50. Mustard WT, Keith JD, Trusler GA, Fowler R, Kidd L (1964) The surgical management of transposition of the great vessels. $J$ Thorac Cardiovasc Surg 48: 953-958.

51. Mustard WT (1964) Successful two-stage correction of transposition of the great vessels. Surgery 55: 469-472. [Crossref]

52. Jatene AD, Fontes VF, Paulista PP, Souza LC, Neger F, et al. (1976) Anatomic correction of transposition of the great vessels. J Thorac Cardiovasc Surg 72: 364-370. [Crossref]

53. Rastelli GC, Wallace RB, Ongley PA (1969) Complete repair of transposition of the great arteries with pulmonary stenosis. A review and report of a case corrected by using a new surgical technique. Circulation 39: 83-95. [Crossref]

54. Rastelli GC, McGoon DC, Wallace RB (1969) Anatomic correction of transposition of the great arteries with ventricular septal defect and subpulmonary stenosis. $J$ Thorac Cardiovasc Surg 58: 545-552. [Crossref]

55. Helbing WA, Hansen B, Ottenkamp J, Rohmer J, Chin JG, et al. (1994) Long-term results of atrial correction for transposition of the great arteries. Comparison of Mustard and Senning operations. J Thorac Cardiovasc Surg 108: 363-372. [Crossref]

56. Wilson NJ, Clarkson PM, Barratt-Boyes BG, Calder AL, Whitlock RM, et al. (1998) Long-term outcome after the mustard repair for simple transposition of the great arteries. 28-year follow-up. J Am Coll Cardiol 32:758-765. [Crossref]

57. Kammeraad JA, van Deurzen CH, Sreeram N, Th E Bink-Boelkens M, Ottenkamp J, et al. (2004) Predictors of sudden cardiac death after Mustard or Senning repair for transposition of the great arteries. J Am Coll Cardiol 44: 1095-1102. [Crossref]

58. Rao PS, Thapar MK (1993) Balloon dilatation of other congenital and acquired stenotic lesions of the cardiovascular system. In: Rao PS (ed): Transcatheter Therapy in Pediatric Cardiology, Wiley-Liss, New York, NY. 275-319.

59. Rao PS, Wilson AD (1992) Chylothorax, an unusual complication of baffle obstruction following Mustard operation: successful treatment with balloon angioplasty. Am Heart $J$ 123: 244-248. [Crossref]

60. Daehnert I, Hennig B, Wiener M, Rotzsch C (2005) Interventions in leaks and obstructions of the interatrial baffle late after Mustard and Senning correction for transposition of the great arteries. Catheter Cardiovasc Interv 66: 400-407.

61. Hurwitz RA, Caldwell RL, Girod DA, Brown J (1996) Right ventricular systolic function in adolescents and young adults after Mustard operation for transposition of the great arteries. Am J Cardiol 77: 294-297. [Crossref]

62. Khairy P, Clair M, Fernandes SM, Blume ED, Powell AJ, et al. (2013) Cardiovascular outcomes after the arterial switch operation for D-transposition of the great arteries. Circulation 127: 331-339. [Crossref]

63. Michalak KW, Moll JA, Moll M, Dryzek P, Moszura T, et al. (2013) The neoaortic root in children with transposition of the great arteries after an arterial switch operation. Eur J Cardiothorac Sur 43: 1101-1108. [Crossref]

64. Hutter PA, Kreb DL, Mantel SF, Hitchcock JF, Meijboom EJ, et al. (2002) Twenty-five years' experience with the arterial switch operation. J Thorac Cardiovasc Surg 124: 790-797. [Crossref]

65. Rao PS (1982) Terminology: tricuspid atresia or univentricular heart? In: Rao PS (ed): Tricuspid Atresia, Mount Kisco, NY, Futura Publishing Co. 3-6.

66. Rao PS (1980) A unified classification for tricuspid atresia. Am Heart J 99: 799-804. [Crossref]
67. Rao PS, Sissman NJ (1971) Spontaneous closure of physiologically advantageous ventricular septal defects. Circulation 43: 83-90. [Crossref]

68. Rao PS, Linde LM, Liebman J, Perrin E (1974) Functional closure of physiologically advantageous ventricular septal defects : observations in three cases with tricuspid atresia. Am J Dis Child 127: 36-40. [Crossref]

69. Rao PS (1977) Natural history of the ventricular septal defect in tricuspid atresia and its surgical implications. Br Heart J 39: 276-288. [Crossref]

70. Rao PS (1983) Further observations on the spontaneous closure of physiologically advantageous ventricular septal defects in tricuspid atresia: surgical implications. Ann Thorac Surg 35: 121-131. [Crossref]

71. Fontan F, Baudet E (1971) Surgical repair of tricuspid atresia. Thorax 26: 240-248. [Crossref]

72. Kreutzer G, Bono H, Galindez E, Palma C, Laura JP (1971) Una operacion para la correccion de la atresia tricuspidea. Ninth Argentinean Congress of Cardiology, Buenos Aires, Argentina, Oct. 31-Nov. 6.

73. Rao PS (2015) Fontan operation: Indications, short and long term outcomes. Indian J Pediatr 82: 1147-1156. [Crossref]

74. Rao PS (2020) Fontan Operation: A Comprehensive Review. In. Khan I. Editor. Fontan Surgery, InTechOpen, Rijeka, Croatia.

75. De Leval MR, Kilner P, Gewilling M, Bull C (1988) Total cavopulmonary connection : a logical alternative to atriopulmonary connection for complex Fontan operation. $J$ Thorac Cardiovasc Surg 96: 682-695. [Crossref]

76. Muller WH, Dammann JF (1952) The treatment of certain congenital malformations of the heart by the creation of pulmonic stenosis to reduce pulmonary hypertension and excessive pulmonary blood flow; a preliminary report. Surg Gynecol Obstet 95:213 219. [Crossref]

77. Norwood WI, Lang P, Castaneda AR, Campbell DN (1981) Experience with operation for hypoplastic left heart syndrome. J Thorac Cardiovasc Surg 82: 511-519. [Crossref]

78. Sano S, Ishino K, Kawada M, Arai S, Kasahara S, et al. (2003) Right ventriclepulmonary artery shunt in first-stage palliation of hypoplastic left heart syndrome. $J$ Thorac Cardiovasc Surg 126: 504-509. [Crossref]

79. Kannankeril PJ, Anderson ME, Rottman JN, Wathen MS, Fish FA (2003) Frequency of late recurrence of intra-atrial reentry tachycardia after radiofrequency catheter ablation in patients with congenital heart disease. Am J Cardiol 92: 879-881. [Crossref]

80. Mavroudis C, Deal BJ, Backer CL (2002) The beneficial effects of total cavopulmonary conversion and arrhythmia surgery for the failed Fontan. Semin Thorac Cardiovasc Surg Pediatr Card Surg Annu 5: 12-24. [Crossref]

81. Goff DA, Blume ED, Gauvreau K, Mayer JE, Lock JE, et al. (2000) Clinical outcome of fenestrated Fontan patients after closure : the first 10 years. Circulation 102: 20942099. [Crossref]

82. Balling G, Vogt M, Kaemmerer H, Eicken A, Meisner H, et al. (2000) Intracardiac thrombus formation after the Fontan operation. J Thorac Cardiovasc Surg 119: 745 752. [Crossref]

83. Varma C, Warr MR, Hendler AL, Paul NS, Webb GD, et al. (2003) Prevalence of "silent" pulmonary emboli in adults after the Fontan operation. J Am Coll Cardiol 41 : 2252-2258. [Crossref]

84. Monagle P, Cochrane A, Roberts R, Manlhiot C, Weintraub R, et al. (2011) Fontan Anticoagulation Study Group. A multicenter, randomized trial comparing heparin/ warfarin and acetylsalicylic acid as primary thromboprophylaxis for 2 years after the Fontan procedure in children. $J$ Am Coll Cardiol 58: 645-651. [Crossref]

85. Chiu NT, Lee BF, Hwang SJ, Chang JM, Liu GC, et al. (2001) Protein-losing enteropathy: diagnosis with $(99 \mathrm{~m})$ Tc-labeled human serum albumin scintigraphy. Radiology 219: 86-90. [Crossref]

86. Feldt RH, Driscoll DJ, Offord KP, Cha RH, Perrault J, et al. (1996) Protein-losing enteropathy after the Fontan operation. J Thorac Cardiovasc Surg 112: 672-680. [Crossref]

87. Giannico S, Hammad F, Amodeo A, Michielon G, Drago F, et al. (2006) Clinical outcome of 193 extracardiac Fontan patients: the first 15 years. J Am Coll Cardiol 47: 2065-2073.

88. Rao PS (2007) Protein-losing enteropathy following the Fontan operation. $J$ Invasive Cardiol 19: 447-448.

89. Masetti P, Marianeschi SM, Cipriani A, Iorio FS, Marcelletti CF (1999) Reversal of protein-losing enteropathy after ligation of systemic-pulmonary shunt. Ann Thorac Surg 67: 235-236. [Crossref] 
90. Mertens L, Dumoulin M, Gewillig M (1994) Effect of percutaneous fenestration of the atrial septum on protein-losing enteropathy after the Fontan operation. Br Heart $J 72$ : 591-592. [Crossref]

91. Lemes V, Murphy AM, Osterman FA, Laschinger JC, Kan JS (1998) Fenestration of extracardiac Fontan and reversal of protein-losing enteropathy: case report. Pediatr Cardiol 19: 355-357. [Crossref]

92. Kreutzer J, Keane JF, Lock JE, Walsh EP, Jonas RA, et al. (1996) Conversion of modified Fontan procedure to lateral atrial tunnel Cavo pulmonary anastomosis. $J$ Thorac Cardiovasc Surg 111: 1169-1176.

93. Marcelletti CF, Hanley FL, Mavroudis C, McElhinney DB, Abella RF, et al. (2000) Revision of previous Fontan connections to total extracardiac cavopulmonary anastomosis : A multicentre experience. J Thorac Cardiovasc Surg 119: 340-346. [Crossref]

94. Lopez JA (2007) Transvenous right atrial and left ventricular pacing after the Fontan operation: long-term hemodynamic and electrophysiologic benefit of early atrioventricular resynchronization. Texas Heart Inst J 34: 98-101. [Crossref]

95. Estner HL, Kolb C, Schmitt C, Deisenhofer I, Pflaumer A, et al. (2008) Long-term transvenous $\mathrm{AV}$-sequential pacing in a failing atriopulmonary Fontan patient. Int $J$ Cardiol 127: e93-95

96. Brancaccio G, Carotti A, D'Argenio P, Michielon G, Parisi F (2003) Protein-losing enteropathy after Fontan surgery : resolution after cardiac transplantation. J Heart Lung Transplant 22: 484-486. [Crossref]

97. Sheikh AM, Tang AT, Roman K, Salmon AP, Monro JL, et al. (2004) The failing Fontan circulation: successful conversion of atriopulmonary connections. $J$ Thorac Cardiovasc Surg 128: 60-66.

98. Gamba A, Merlo M, Fiocchi R, Terzi A, Mammana C, et al. (2004) Heart transplantation in patients with previous Fontan operations. J Thorac Cardiovasc Surg 127: 555-562. [Crossref]

99. Jayakumar KA, Addonizio LJ, Kichuk-Chrisant MR, et al. (2004) Cardiac transplantation after the Fontan or Glenn procedure. J Am Coll Cardiol 44:2065-2072. [Crossref]

100. John S, Sukumar IP, Muralidharan S, Jairaj P, Krishaswami S, et al. (1981) Total anomalous pulmonary venous return in children and adults. Results of corrective surgery. J Cardiovasc Surg (Torino) 22: 9-14. [Crossref]
101. Berg GA, Jamieson MP, Pollock JC (1986) Repair of total anomalous pulmonary venous connection in adults. Thorac Cardiovasc Surg 34: 359-361.

102. Joy J, Subramanyan R, Balakrishnan KG (1987) Total anomalous pulmonary venous connection (TAPVC) in children and adults: a pre- and post-operative study. Indian Heart J 39: 340-346.

103. Rodríguez-Collado J, Attie F, Zabal C, Olvera S, Vázquez J, et al. (1992) Total anomalous pulmonary venous connection in adults. Long-term follow-up. $J$ Thorac Cardiovasc Surg 103: 877-880. [Crossref]

104. Ashoush R, Jebara VA, el Rassi I, Badawi G, Sarkis A, et al. (1993) Total anomalous pulmonary venous connection in adults--a surgical review. J Med Liban 41: 230-235. [Crossref]

105. Jian XH, Huang J, Ding Y, Xiao XJ, Wu M, et al. (2012) Surgical outcome of isolated total anomalous pulmonary venous connection in adults : a 14 -year experience. $J$ Card Surg 27: 736-739. [Crossref]

106. Lev M, Saphir O (1942) Truncus arteriosus communis persistens. J Pediatr 20: 74-84.

107. Ebert PA, Turley K, Stanger P, Hoffman JI, Heymann MA (1984) Surgical treatment of truncus arteriosus in the first 6 months of life. Ann Surg 200: 451-456. [Crossref]

108. Lund AM, Vogel M, Marshall AC, Emani SM, Pigula FA, et al. (2011) Early reintervention on pulmonary arteries and right ventricular outflow tract after neonata or early infant repair of truncus arteriosus using homograft conduits. Am J Cardiol 108: 106-113. [Crossref]

109. Carol WF, McKenzie ED, Slesnick TC (2011) Root dilatation in patients with truncus arteriosus. Congenit Heart Dis 6: 228-233. [Crossref]

110. Rao PS (2013) Consensus on timing of intervention for common congenital heart diseases: Part II - Cyanotic heart defects. Indian J Pediatr 80: 663-674. [Crossref]

111. Rao PS (2019) Management of congenital heart disease: State of the art-Part IICyanotic heart defects. Children (Basel) 6: 54. [Crossref]

112. Rao PS (2020) Cyanotic congenital heart defects. In: Rao PS. Pediatric Cardiology: How It Has Evolved Over the Last 50 Years. Cambridge Scholars Publishing, New Castle upon Tyne, 604-633.

Copyright: (C2020 P. Syamasundar Rao. This is an open-access article distributed under the terms of the Creative Commons Attribution License, which permits unrestricted use, distribution, and reproduction in any medium, provided the original author and source are credited. 